\title{
Revisions to information for authors
}

\author{
Richard D. Weisel, MD
}

With the new year, the Journal will assume a new look and will have new features. In the Editor's Notes for February, we provide the changes we are making to the information for authors to assist their submission of papers to the Journal.

New General Information: The Editors of The Journal of Thoracic and Cardiovascular Surgery aspire to support scholarship, innovation, and leadership in our specialty. The mission of the Journal is to promote quality in our discipline and have a meaningful impact on the practice of cardiothoracic surgery. To accomplish these goals, the Journal accepts a wide range of articles related to surgery for acquired and congenital cardiovascular disease, cardiothoracic transplantation, and general thoracic surgery, as well as papers on evolving technology and basic science, perioperative medicine, and education and training.

Revised Categories of Publications: Original articles, expert reviews, expert opinions, description of surgical techniques, cardiothoracic images, and case reports for online only publication.

Revised Authorship Policy: Only those individuals who made direct contributions to the intellectual content of the paper may be listed as authors. The cover letter should describe the contribution of each author.

Revised Policy on Scientific Responsibility: The Journal is committed to rigorous peer review, free from commercial influence, in order to promote the highest ethical and scientific standards. The support received from any sources should be disclosed for each author. The editors and reviewers will determine whether any of the relations constitute a conflict of interest that may have biased the material presented in the paper. Many JTCVS authors are advisors or consultants for companies that develop innovative technology and pharmaceuticals. Authors with extensive commercial relations provide important contributions to the readers of the Journal. However, the information must be presented with an appropriate scientific balance that is unbiased and based on objective data. The reviewers and the editors will attempt to ensure that balance.

From the Division of Cardiovascular Surgery, Toronto General Hospital, Research Institute and the University of Toronto, Toronto, Ontario, Canada.

Disclosures: Author has nothing to disclose with regard to commercial support.

Address for reprints: Richard D. Weisel, MD, 200 Elizabeth St 4N-476, Toronto,

Ontario, Canada M5G 2C4 (E-mail: rweisel@uhnresearch.ca).

J Thorac Cardiovasc Surg 2015;149:414-5

$0022-5223 / \$ 36.00$

Copyright (C) 2015 by The American Association for Thoracic Surgery

http://dx.doi.org/10.1016/j.jtcvs.2014.12.011

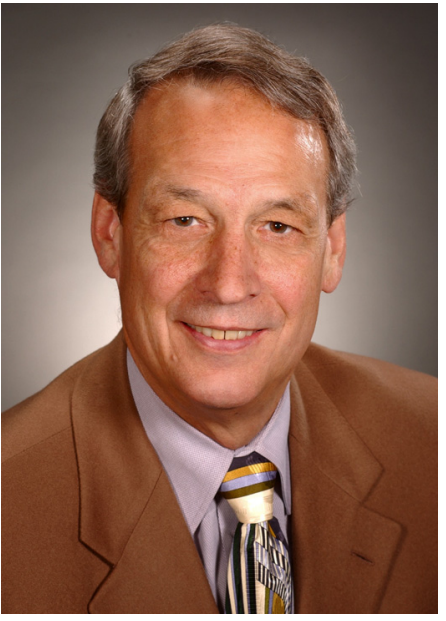

New Open Access: The authors have a choice to publish their research as open access once the author proofs are approved.

Revised Policy on Statistical Methods: The conclusions for all papers should be supported by the highest quality evidence and adequate statistical methods. Therefore, authors who employ any complex statistical methods must have their paper reviewed by a qualified biostatistician prior to submission. All manuscripts employing complex statistics will be reviewed by experts in scientific methods and statistics to ensure an adequate and appropriate study design, analysis, interpretation, and reporting have been achieved.

New Opportunity to Suggest Reviewers: Authors are requested to suggest at least two reviewers who they believe to be expert and impartial in the field of the manuscript. These reviewers may be selected at the Editors' discretion.

New Instructions for Preparation of the Papers:

Title: Provide a concise, informative title, with no unnecessary words.

Authors: For each author provide: Academic degrees and affiliations, including their institutions, departments, and divisions. Indicate all sources of funding for the work, and all possible conflicts of interest should be listed on the title page.

Author Perspective: Provide 2 to 6 sentences totaling no more than 100 words to indicate the significance of the findings for the field and how the authors anticipate that their results may impact clinical practice. For basic science studies, this section should indicate the clinical relevance of the findings and how the results may impact clinical practice some day in the future. 
TABLE 1. Length requirements

\begin{tabular}{|c|c|c|c|c|c|c|c|}
\hline & Authors & $\begin{array}{c}\text { Structured } \\
\text { abstract }\end{array}$ & Text & References & $\begin{array}{l}\text { Figures/tables (including } \\
\text { central picture) }\end{array}$ & $\begin{array}{c}\text { Author } \\
\text { perspective }\end{array}$ & $\begin{array}{l}\text { Central } \\
\text { message }\end{array}$ \\
\hline Original Article & 7 & 250 & 3500 & 35 & 7 & 100 & 50 \\
\hline Expert Review & 4 & 250 & 2500 & 25 & 4 & 100 & 50 \\
\hline Expert Opinion & 4 & 250 & 2500 & 25 & 4 & 100 & 50 \\
\hline Surgical Technique or Case Report & 4 & NA & 750 & 5 & 2 & NA & 50 \\
\hline Invited Editorial Commentary & 4 & NA & 500 & 10 & 2 & NA & 50 \\
\hline Invited Editorial & 4 & NA & 2500 & 25 & 4 & 100 & 50 \\
\hline
\end{tabular}

Additional materials (text, figures, tables) can be included as online supplemental material. $N A$, Not applicable.

Central Picture: The authors should designate 1 of their figures or provide a separate picture that summarizes an important component of their manuscript to provide a snapshot of the paper with a single memorable visual image. The central picture should be accompanied by an abbreviated legend. This figure will appear on the first page of the manuscript and in both the print and electronic tables of contents.

Central Message: Provide 1 to 3 sentences totaling no more than 50 words which contain the essence of the findings-the message of the paper. This section replaces the Ultramini Abstract and will be inserted beneath the title of the paper in the table of contents.

Checklist for Initial Article Submission

\section{Cover Letter}

Title page

Title of article

Full name(s), academic degrees, and affiliation(s) of authors

Corresponding author

Telephone and email address for corresponding author

Word count (required)
Abstract (250 words; double-spaced; for article types listed in Table 1)

Author Perspective Statement (100 words)

Central Picture and legend

Central Message (50 words)

Conflict of Interest statement

Text (double-spaced)

References (double-spaced; separate pages)

Tables (double-spaced; separate pages)

Figure legends (double-spaced; separate pages)

Figures

Permission to reproduce published material or to cite unpublished data (if applicable)

Informed consent statement (in Methods)

Humane animal care statement (in Methods)

Role of funding agency in data interpretation (in Methods)

Clinical Trial Registry Number (if applicable)

The new look for the Journal will have new requirements to submit papers. We hope that you like the changes. 